\title{
Productivity, biochemical indices and antioxidant activity of Peppermint (Mentha piperita L.) and Basil (Ocimum basilicum L.) in condition of hydroponics
}

\section{Stepan Mairapetyan ${ }^{1 *}$, Juletta Alexanyan ${ }^{1}$, Anahit Tovmasyan ${ }^{1}$, Mahsa Daryadar ${ }^{1}$, Bella Stepanian $^{1}$ and Vardan Mamikonyan ${ }^{2}$}

${ }^{1}$ National Academy of Sciences, G. S. Davtyan Institute of Hydroponics Problems, Armenia ${ }^{2}$ Scientific Technological Center of Organic and Pharmaceutical Chemistry NAS RA, Armenia

\begin{tabular}{|c|c|}
\hline Article Info. & ABSTRACT \\
\hline $\begin{array}{l}\text { Key Words: } \\
\text { Water-stream } \\
\text { hydroponics, Peppermint, } \\
\text { Sweet basil, Extractives, } \\
\text { Antioxidant, Productivity } \\
\text { Received: } 04.03 .2016 \\
\text { Published: } 25.05 .2016 \\
\text { Contact author*: } \\
\text { hydrop@netsys.am }\end{array}$ & $\begin{array}{l}\text { Dry raw material of both peppermint and sweet basil grown with the } \\
\text { application of different hydroponic methods (cylindrical, gully, continuous, } \\
\text { classical) exceeds soil culture } 1.2-2.7 \text { and } 1.8-2.7 \text { times. At the same time a } \\
\text { high output (1.6-3.1 times) of secondary origin bioactive substances was } \\
\text { observed in cylindrical and classical hydroponics systems due to the high } \\
\text { productivity of peppermint and in the case of basil in cylindrical } \\
\text { hydroponics system (1.2-2.9 times). For determining antioxidant activity } \\
\text { from different quantity of alcoholic extracts obtained from the mentioned } \\
\text { plants the more effective is chosen in peppermint } 5.0 \mathrm{mg} / \mathrm{ml} \text { in which case } \\
\text { free radical oxidation process of lipids is repressed from } 68-84 \% \text {, and in } \\
\text { case of basil } 1.0 \mathrm{mg} / \mathrm{ml} 23-31 \% \text {. }\end{array}$ \\
\hline
\end{tabular}

Citation (APA): Mairapetyan, S., Alexanyan, J., Tovmasyan, A., Daryadar, M., Stepanian, B. \& Mamikonyan, V. (2016). Productivity, biochemical indices and antioxidant activity of Peppermint (Mentha piperita L.) and Basil (Ocimum basilicum L.) in condition of hydroponics. Journal of Science, Technology \& Environment Informatics, 03(02), 191-194.

(C) 2016, Mairapetyan et al. This is an open access article distributed under terms of the Creative Common Attribution 4.0 International License.

\section{Introduction}

Environmental pollution threatens the health of humans, and can also disturb plant and animal diversity. It causes normal activity deterioration of bio systems (Allaby, 2000; Ghalachyan et al., 2014). Nowadays, antioxidants, which are an integral part of biologically active substances, are of great interest. They can reduce mutagenic influence, regulating the oxidation process of free radicals. Therefore, discovery and studies of natural sources with antioxidant activity is an urgent problem now. According to literature, a number of biologically active substances, which are produced by plants and 
have antioxidant activity, are known. They include $\alpha$-tocoferol (vitamin E), tannins, ascorbic acid (vitamin C), $\beta$ - carotene, a number of protein compounds with enzymatic activity, flavonoids, polysaccharides, terpenoids, polyphenol compounds and etc. (Gordienko et al., 1987; Fridovich, 1997; Durnev et al., 2002; Wiliams et al., 2004; Gromovaya et al., 2008; Sajina, 2010). Similar studies were also carried out in Hypericum perforatum L., Thymus marschalliamus W. and Callisia fragrans L. Woodson plant raw material grown in soilless culture (hydroponics) conditions. The extracts of the tested samples had a positive antiradical activity (Sargsyan and Vardanyan, 2012; Vardanyan and Sargsyan, 2014; Malakyan, 2015). Antioxidants are widely used in medicine, agriculture, as well as chemistry and food industry. Lack of antioxidants in organism, as stated above, promotes the oxidation process activity of free radicals, which in turn causes a variety of pathological conditions and for development. Regulation of antioxidant levels promotes prolongation of life expectancy, strengthens the immune system. Peppermint (Mentha piperita L.) and sweet basil (Ocimum basilicum L.) are among the most popular essential oil and medicinal plants, which are widely used in medicine, pharmaceutics and perfume production. At the same time, they are used as a spice (in the form of tea) and have antioxidant properties (Mairapetyan et al., 2013; Daryadar, 2014). Taking into account the unique properties of peppermint and sweet basil, our aim is to study the comparative description of productivity, biochemical indices and antioxidant properties of these plants, grown in water stream hydroponics ${ }^{1}$ (cylindrical, gully, continuous), classical hydroponics and soil culture (control) conditions.

\section{Materials and Methods}

Planting material of peppermint and sweet basil, obtained with hydroponics method, were used during the experiments. $3-15 \mathrm{~mm}$ particle diameter volcanic slag was used as a substrate in all the hydroponics systems. The plants were nourished with G.S. Davtyan's nutrient solution (Davtyan, 1980). The content of essential oil, extractives, tannins in dry raw material was determined with SPh XI (SPh XI, 1990), flavonoids with Borisov's method (Borisov et al., 1975), the antioxidant activity (AO) of plants in extractives was determined with malonic dialdehyde quantitative determination method (Vladimirov et al., 1991). In order to determine antioxidant activity of peppermint and sweet basil different dosages $(0.5 ; 1.0 ; 2.0 ; 5.0 \mathrm{l} 10.0 \mathrm{mg} / \mathrm{ml})$ of extractives was taken from the mentioned plants. Among them, $5.0 \mathrm{mg} / \mathrm{ml}$ was chosen as the most effective variant for peppermint and $1.0 \mathrm{mg} / \mathrm{ml}$ for sweet basil. The studies were carried out in liver homogenate, lipid peroxidation processes were activated with the application $0.5 \mathrm{ml}(15.7 \mathrm{mg} / \mathrm{l})$ water solution of Mohr's Salt (MS) [ $\mathrm{FeSO}_{4} \bullet\left(\mathrm{NH}_{4}\right)_{2} \mathrm{SO}_{4} \bullet 6 \mathrm{H}_{2} \mathrm{O}$ ] Alcoholic extracts of peppermint and sweet basil were used as possible antioxidants. The number of experiment replications was 4-8; mathematical modeling was done according to Dospekhov (Dospekhov, 1985).

\section{Results and Discussion}

Growth peculiarities and productivity indices of the studied plants in hydroponics and soil culture conditions vary significantly. It is the result of regulating a number of factors, particularly food-airwater mode, which provide growth, development and productivity of hydroponics plants. We can see from the analysis of table 1 and 2 that planting material of both peppermint and sweet basil, obtained with application of different hydroponics methods, exceeded soil culture 1.2-2.7 and 1.8-2.7 times with dry weight. At the same time, due to high productivity of peppermint, maximum output of essential oils (1.6-2.6 times), extractives (1.7-3.1 times), flavonoids (1.6-2.3 times) and tannins (1.6-2.8 times) was provided by cylindrical and classical hydroponics systems. In case of sweet basil the output (per plant) of the above mentioned compounds, except tannins, increases 1.2-2.7; 1.5-2.8; 1.3-2.9 times, respectively, compared to the other tested variants.

\footnotetext{
${ }^{1}$ Developing new and low cost hydroponics systems is one of the most important issues for increasing the economic efficiency of plant soilless culture and its wide spread in the world. The most promising among them is water-stream hydroponics system developed in Institute of Hydroponics Problems NAS RA the result of 25-year investigations, with use of polymer film which enables to sharply decrease (5-6 times) expenditures for building a hydroponicum (Mairapetyan et al., 2007).
} 
J. Sci. Technol. Environ. Inform. 03(02): 191-194 | Mairapetyan et al. (2016)

EISSN: 2409-7632, journalbinet.com

DOI: http://dx.doi.org/10.18801/jstei.030216.21

Table 01. Content and output of substances determining pharmacochemical value of peppermint in conditions of different hydroponics systems and soil culture

\begin{tabular}{|c|c|c|c|c|c|c|c|c|c|}
\hline \multirow[t]{2}{*}{ Variant } & \multirow[t]{2}{*}{$\begin{array}{l}\text { Dry weight of medicinal } \\
\text { raw material, g/plant }\end{array}$} & \multicolumn{2}{|c|}{ Essential oil } & \multicolumn{2}{|c|}{ Extractives } & \multicolumn{2}{|c|}{$\begin{array}{c}\text { Sum } \\
\text { flavonoids }\end{array}$} & \multicolumn{2}{|c|}{ Tannins } \\
\hline & & $\%$ & g/plant & $\%$ & $\mathrm{~g} /$ plant & $\%$ & $\mathrm{~g} /$ plant & $\%$ & $\mathrm{~g} /$ plant \\
\hline Cylindrical & 155.0 & 3.98 & 6.15 & 20.63 & 32.0 & 2.80 & 4.3 & 14.76 & 22.9 \\
\hline Gully & 83.7 & 4.16 & 3.48 & 18.16 & 15.2 & 3.0 & 2.5 & 13.96 & 11.7 \\
\hline Continuous & 69.7 & 3.93 & 2.74 & 20.20 & 14.1 & 3.16 & 2.2 & 14.34 & 10.0 \\
\hline $\mathrm{CH}$ & 149.0 & 3.80 & 5.66 & 17.23 & 25.7 & 2.66 & 4.0 & 12.56 & 18.7 \\
\hline $\begin{array}{l}\text { Soil } \\
\text { (control) }\end{array}$ & 57.0 & 4.09 & 2.33 & 18.07 & 10.3 & 3.26 & 1.9 & 14.63 & 8.3 \\
\hline $\mathrm{LED}_{05}$ & 15.3 & & & & & & & & \\
\hline
\end{tabular}

Average data of three cuts are shown.

Table 02. Content and output of substances determining pharmacochemical value of sweet basil in conditions of different hydroponics systems and soil culture

\begin{tabular}{|c|c|c|c|c|c|c|c|c|c|}
\hline \multirow[t]{2}{*}{ Variant } & \multirow{2}{*}{$\begin{array}{l}\text { Dry weight of } \\
\text { medicinal raw } \\
\text { material, } \\
\text { g/plant }\end{array}$} & \multicolumn{2}{|c|}{ Essential oil } & \multicolumn{2}{|c|}{ Extractives } & \multicolumn{2}{|c|}{ Sum flavonoids } & \multicolumn{2}{|c|}{ Tannins } \\
\hline & & $\%$ & $\mathrm{~g} /$ plant & $\%$ & g/plant & $\%$ & g/plant & $\%$ & $\mathrm{~g} /$ plant \\
\hline Cylindrical & 85.3 & 0.77 & 0.66 & 26.78 & 22.84 & 2.72 & 2.32 & 8.72 & 7.44 \\
\hline Gully & 75.2 & 0.74 & 0.56 & 18.45 & 13.87 & 2.10 & 1.58 & 10.36 & 7.79 \\
\hline Continuous & 57.4 & 0.82 & 0.47 & 26.25 & 15.07 & 2.44 & 1.40 & 10.81 & 6.20 \\
\hline $\mathrm{CH}$ & 61.3 & 0.60 & 0.37 & 25.28 & 15.50 & 2.91 & 1.78 & 8.18 & 5.01 \\
\hline Soil & 31.3 & 0.78 & 0.24 & 26.30 & 8.2 & 2.42 & 0.76 & 8.56 & 2.67 \\
\hline $\mathrm{LED}_{05}$ & 12.8 & & & & & & & & \\
\hline
\end{tabular}

Average data of three cuts are shown.

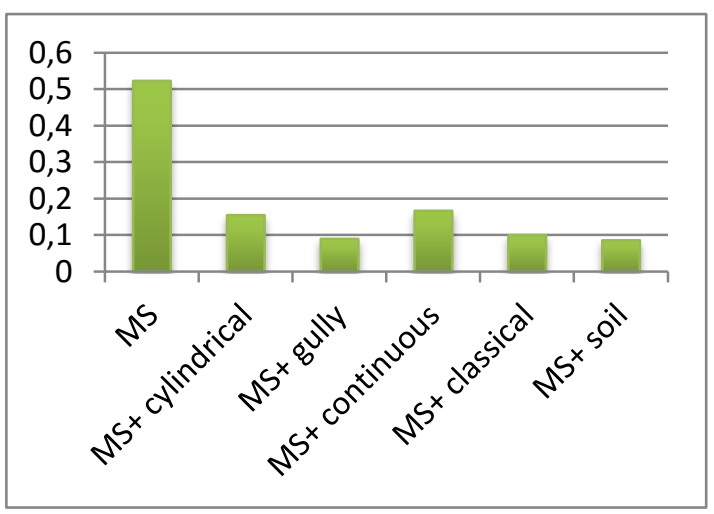

(a)

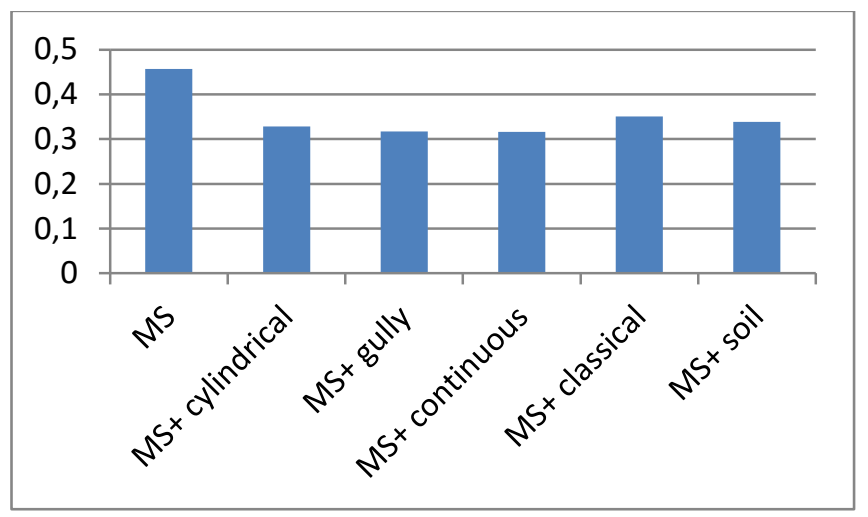

(b)

Figure 01. Peppermint (a) and sweet basil (b) antioxidant activity, $\%$ in conditions of different hydroponics systems and soil culture.

It is obvious from the analysis that cultivation conditions affected peppermint antioxidant activity. Planting material grown in cylindrical and continuous hydroponics systems had less antioxidant properties; it was inferior to other variants 1.6-1.9 times. While, in case of sweet basil the difference is not significant. However, free radical oxidation processes of lipids were repressed in both cases. In case of peppermint it is $68-84 \%$ and in case of sweet basil $23-31 \%$ (Figure 01 ). It is also neccessary to note that high productivity of the crops tested in cylindrical hydroponics system, in turn, promoted the output increase of the above mentioned compound 1.6-4.9 and 1.2-2.6 times. 


\section{Conclusion}

Dry raw material of both peppermint and sweet basil obtained with the application of different hydroponic methods exceeds soil culture 1.2-2.7 times. A high output (1.2-3.1 times) of secondary origin bioactive substances was obtained in plant raw material of peppermint and sweet basil grown in different hydroponics systems. Peppermint and sweet basil grown in conditions of different hydroponics systems and soil culture can be natural sources of antioxidants. Antioxidant activity of $5 \mathrm{mg} / \mathrm{ml}$ peppermint was $68-84 \%$ and in case of $1 \mathrm{mg} / \mathrm{ml}$ sweet basil $23-31 \%$.

\section{References}

[1]. Allaby, M. (2000). Basics of Environmental Science. 2nd edition. Routledge. London. pp. 1-17.

[2]. Borisov, M. I., Belikov, V. V., Isakov, T. I. (1975). The quantitative content of flavonoids in Asperula L. and Galium L. Plant resources, V. 11 (3rd ed.), 351-358.

[3]. Daryadar, M. Kh. (2014). The Productivity of Ocimum Basilicum L. in the Newest Experimental Modules of Water Stream Hydroponics. Journal of Applied Environmental and Biological Sciences, 4(2), 284-288.

[4]. Davtyan, G. S. (1980). Hydroponics. Reference Book for chemicals used in agriculture. M. Kolos, p. 382-385. (Russian)

[5]. Dospekhov, B. A. A. (1985). Technique of field experiment. M. 1985, p. 351, pp. 223-228. (Russian)

[6]. Durnev, A. D., Nikitina, V. A. \& Vrjesinskaya, O. A. (2002). Influence of taking vitamins on the sensitivity of peripheral blood lymphocytes to the clastogenic action of mutagens in vitro. Bulletin of Experimental Biology and Medicine, 134(9), 303-307. (Russian)

[7]. Fridovich, I. (1997). Superoxide anion radikal (02), superoxide dismutases and related matters. JBC Online, 272 (30), 18515-18517.

[8]. Ghalachyan, L. M., Asatryan A. Z., Kocharyan K. A. \& Tadevosyan L.S. (20144. The accumulation of artificial radionuclides in spice herbs in different zones under the impact of the Armenian NPP. Bulletin of State Agrarian University of Armenia, 2, 17-20.

[9]. Gordienko, A. D., Komisarenko, N. F. \& Levchenko, V. V. (1987). Antioxidant properties of natural phenols. Rep. of the Fifth All-Union Symp. on phenol compounds, 32-33. (Russian)

[10]. Gromovaya, V. F., Shapoval, G. S., Mironyuk, I. E. \& Nestyuk, N. V. (2008). Antioxidant properties of medicinal plants. Pharmacoceutical Chemistry Journal, 42 (1), 25-28.

http://dx.doi.org/10.1007/s11094-008-0050-9

[11]. Mairapetyan, S. Kh., Daryadar M. Kh., Alexanyan J. S., Tadevosyan A. H., Tovmasyan A. H., Stepanyan B. T. \& Galstyan H. M. (2013). Comparative description of productivity and content of biologically active substances of some essential, oil-bearing plants in condition of new water stream hydroponics. Biological Journal of Armenia, 3(65), 80-84.

[12]. Mairapetyan, S. Kh., Tadevosyan, A. H., Hovsepyan, A. H. \& Mayrapetyan, Kh. S. (2007a). Method of soilless cultivation of plants and their implementation system. Invention Patent of RA, № 1946, A2. (Armenian)

[13]. Mairapetyan, S. Kh., Tadevosyan, A. H., Hovsepyan, A. H. \& Mayrapetyan, Kh. S. (2007b). Method of soilless cultivation of sowed herbs and their implementation system. Invention Patent of RA, №1988 A2. (Armenian)

[14]. Mairapetyan, S. Kh., Tadevosyan, A. H., Hovsepyan, A. H. \& Mayrapetyan, Kh. S. (2007c) "Method of soilless cultivation of herbs and their implementation system", Invention Patent RA, № 1989 A2. (Armenian)

[15]. Malakyan, M. H., Karapetyan, A. S. \& Mairapetyan, S. Kh. (2015). Radioprotective activity of Callisia fragrans grown in soilless (hydroponics) and soil culture conditions. Electronic Journal of Natural Sciences, 20-23.

[16]. Sajina, N. N., Misin, V. M. \& Korotkowa, E. I. (2010). Investigation of antioxidant properties of aqueous extract of mint electrochemical methods. Chemistry of plant raw materials, 4, 77-82. (Russian) 
[17]. Sargsyan, E. D. \& Vardanyan, A. P. (2012). The study of antioxidant activity of hydroponic and wild medicinal plants Thyme Marshal. Proceedings of XXI international symposium "Protection of bio-noosphere. Eniology. Non-traditional crop. Ecology and medicine", September 9-16, 2012, Alushta, Simferopol, pp. 434-438. (Russian).

[18]. SP. (1990). State Pharmacopoeia of the USSR, XI ed., Moscow: Medicine, 1990, www.fito.nnov.ru/pharmacopaea. (Russian)

[19]. Vardanyan, A. P. \& Sargsyan, E. D. (2014). Studies on antiradical activity of hydroponic Hypericum Perforatum L. medicinal raw material. Bulletin of National Agrarian University of Armenia, 3(47). International Scientific Jurnal. 37-40. (Russian)

[20]. Vladimirov, Y. A., Azizova, O. A., Deev, A. I. \& Kozlov, A. V. (1991). Free radicals in living systems. Results of science and technology, Moscow, VINTI, v. 29,126-130. (Russian)

[21]. Wiliams, R. J., Spencer, J. P., Rice-Evans, C. (2004). Flavonoids: antioxidants or signaling molecules. Free Radical Biology \& Medicine, 36 (7), 838-849.

http://dx.doi.org/10.1016/j.freeradbiomed.2004.01.001 